\title{
EDITORIAL
}

\section{Bronchodilator testing: an endless story}

\author{
R. Pellegrino, A. Antonelli and M. Mondino
}

$\mathbf{T}$ he history of the bronchodilator test dates back to the late 1950s when airway diseases were classified as reversible or irreversible depending on the response to bronchodilators [1, 2]. The hope to differentiate asthma from chronic obstructive pulmonary disease (COPD) on this basis was such that the test soon gained popularity in clinical practice. Two large trials published in the mid 1980s, however, dimmed the original enthusiasm on such a test because no clear cut-off was found between asthmatic and COPD patients $[3,4]$. In addition, the response depended on several factors, such as definition and severity of airflow obstruction and spirometric parameter considered for the functional response to the dilator agent together with its relevant threshold of natural variability. Finally, the test was scarcely reproducible over time in the individual patients. Somehow, these two studies challenged the common notion of that time that airway reversibility was a typical and unique feature of bronchial asthma.

After more than two decades of intensive study and a long series of negative and positive publications on this issue, bronchoreversibility testing is still largely used in clinical practice and deemed to guide the clinician through the diagnostic and follow-up process $[5,6]$. For instance, large increments in the forced expiratory volume in $1 \mathrm{~s}$ (FEV1) $>400 \mathrm{~mL}$ after an acute dose of salbutamol support the diagnosis of asthma in patients with a history compatible with the disease [7], though prospective studies confirming the validity of such a threshold have never been published and the role of similar improvements in forced vital capacity (FVC) in this respect has not been documented. A positive response of FEV1 and/or FVC or vital capacity (VC) above $12 \%$ and $200 \mathrm{~mL}$ baseline value will lend support to bronchodilator therapy independently of the underlying disease. Even a "negative" response, i.e. an increase in either FEV1 or FVC or VC below $12 \%$ and $200 \mathrm{~mL}$ baseline value may be often associated with reduction in dyspnoea. In $>50 \%$ of the cases, this is consistent with significant improvements in airway function, as suggested by increments in partial flow and airway conductance, and decrements in the operational lung volumes well beyond the threshold of natural variability, thus supporting the indication to continuous therapy even in these cases [8]. An increase in FVC or VC from low to normal values after inhaling a bronchodilator agent may also be of help to exclude the coexistence of restriction in any obstructive lung disease, if absolute lung volumes cannot be measured. The use

Allergologia \& Fisiopatologia Respiratoria, ASO S. Croce e Carle, 12100 Cuneo, Italy.

CORRESPONDENCE: R. Pellegrino, Allergologia \& Fisiopatologia Respiratoria, ASO S. Croce e Carle, 12100 Cuneo, Italy. E-mail: pellegrino.r@ospedale.cuneo.it of the post-bronchodilator values is also indicated for the diagnosis of COPD, as suggested by current clinical guidelines [5]. Finally, lung function changes after a bronchodilator agent may help identify the presence and extent of emphysema in COPD patients [9]. Collectively, all these reasons represent a solid clinical ground for the use of the bronchodilator testing in routine evaluation of obstructive lung diseases.

In this issue of the European Respiratory Journal, HaN et al. [10] add new information in this field and document the presence of bronchoreversibility, even in COPD with moderate-tosevere emphysema. By reviewing data from 544 COPD patients with severe bilateral emphysema participating in the National Emphysema Treatment Trial, the authors observed that, despite that only a quarter of the patients exhibited a significant increase in the FEV1 on one or more occasions, twothirds of the population exhibited impressive increments in FVC $>400 \mathrm{~mL}$. Very similar results have already been observed in 1982 by HugHes et al. [11] in emphysematous COPD patients after inhaling fenoterol. Apart from a slight confusion in the ERS/ATS guidelines on lung function testing that actually define a positive response to bronchodilators as an increase in the FEV1 and/or FVC $>12 \%$ control and $200 \mathrm{~mL}$ [6], these data are of great import in respiratory medicine for a series of reasons. For instance, to the extent that an increase in FVC reflects clinical improvements in dyspnoea at rest and during physical activity $[12,13]$, these data add further support to the notion that COPD is not a fully irreversible disease, as recently suggested in two large clinical trials [14, 15] and underlined in the new definition of the disease by the Global Initiative for Chronic Obstructive Lung Disease (GOLD) guidelines [5]. If so, the regular use of bronchodilator agents in COPD with moderate emphysema would appear to be justified in clinical practice. Another important novelty of the study is that the effects of salbutamol on FVC gradually wane with the increase in amount of emphysema. The reasons for this are unknown and cannot be determined from the results of the present study. However, these data open the question as to whether phenotyping the disease into chronic bronchitis and emphysema subsets is important in clinical practice. Current guidelines do not insist on the determination of the predominant phenotype in individual patients $[5,7]$ and the recent large clinical trials on steroids and bronchodilators did not examine the response to bronchodilators and/or clinical outcomes as a function of the underlying phenotype [16-21]. In contrast, the present data appear to corroborate our common clinical sense and experience that COPD patients with severe emphysema do not respond to bronchodilator agents as much as patients with prevalent intrinsic airway narrowing. Might these findings help explain some of the negative results of many clinical trials investigating the effects 
of bronchodilators or steroids in COPD [16-21]? We believe they possibly do. Indeed, by enrolling COPD patients with either pulmonary emphysema or chronic bronchitis, the possibility exists that the positive effects in the latter were somewhat obscured by the blunted responses in the emphysematous patients. In any case, labelling COPD patients in clinical practice has a series of important advantages, among which we recall the help in directing the pharmacological research towards new treatments capable of targeting the real mechanisms and not just the epiphenomena of the disease, facilitating the examination of the findings of the epidemiological trials, and easing our relationship with patients whose expectations need to be nowadays addressed with great honesty. Another interesting finding in the HAN et al. [10] study is that females exhibited less bronchodilation than males. Far from giving any interpretation to the finding, it is worth recalling that geometric differences in airway calibre and wall size and possible different responses to inhaled toxic particles and gases between sexes may play an important role in this respect; however, this has to be evaluated in future studies. Finally, we would like to comment on the clinical relevance of the low reproducibility over time of the test in COPD. Since short- and long-term responses to bronchodilators have not been found to be correlated to each other [14], the bronchodilator test has been abandoned by some guidelines [7] for this and presumably other reasons. From a functional point of view, however, fluctuation of the bronchodilator response should not be underestimated as it presumably reflects the ephemerality of the disease and might perhaps predict acute exacerbations.

Is there a future for the bronchodilator tests? So far, most of the research in this field has been conducted with the analysis of maximal flow and, in rare cases, with lung volumes. In a recent study, DellacÀ et al. [22] applied the forced oscillation technique (FOT) to assess the response to salbutamol in conjunction with classic parameters in a group of 20 COPD patients. They found that expiratory flow limitation within the tidal breathing had critical effects on the response of resting lung parameters, but this was somewhat unrelated to the changes in the operational lung volumes. The complexity of such a response could not have been made possible without the use of the FOT, a technique capable of providing instantaneous assessment of airway calibre and ventilation homogeneities at any lung volumes, thus opening new frontiers in investigating the response of any airway disease to bronchodilators in conjunction with the classical spirometric parameters. In view of the current trend to combine $\beta_{2}$-agonists with anticholinergic medications in the treatment of COPD [23, 24], these new techniques will reveal of great help in detecting the real effects of such medications on airway mechanics in the obstructive lung diseases.

\section{STATEMENT OF INTEREST}

None declared.

\section{REFERENCES}

1 Terminology, definitions, and classification of chronic pulmonary emphysema and related conditions, a report of the conclusions of a Ciba guest symposium. Thorax 1959; 14: 286-299.
2 American Thoracic Society. Committee on diagnostic standards for non tuberculous respiratory diseases: chronic bronchitis, asthma, and pulmonary emphysema. Am Rev Respir Dis 1962; 85: 762-768.

3 Eliasson O, Degraff AC Jr. The use of criteria for reversibility and obstruction to define patient groups for bronchodilator trials. Influence of clinical diagnosis, spirometric, and anthropometric variables. Am Rev Respir Dis 1985; 132: 858-864.

4 Anthonisen NR, Wright EC, the IPPB trial group, Bronchodilator response in chronic obstructive pulmonary disease. Am Rev Respir Dis 1986; 133: 814-819.

5 Global strategy for diagnosis, management and prevention of COPD. Global initiative for chronic obstructive lung disease (GOLD). 2007. www.goldcopd.org Date last accessed: December 15, 2009.

6 Pellegrino RC, Viegi G, Brusasco V, et al. Interpretive strategies for lung function tests. Eur Respir J 2005; 26: 948-968.

7 Chronic obstructive pulmonary disease. National clinical guideline on management of chronic obstructive pulmonary disease in adults in primary and secondary care. Thorax 2004; 59: Suppl. I, 1-232.

8 Pellegrino R, Rodarte JR, Brusasco V. Assessing the reversibility of airway obstruction. Chest 1998; 114: 1607-1612.

9 Cerveri I, Dore R, Corsico A, et al. Assessment of emphysema in COPD: a functional and radiological study. Chest 2004; 125: 17141718.

10 Han MK, Wise R, Mumford J, et al. Prevalence and clinical correlates of bronchoreversibility in severe emphysema. Eur Respir J 2010; 35: 1048-1056.

11 Hughes JA, Tobin MJ, Bellamy D, et al. Effects of ipratropium bromide and fenoterol aerosols in pulmonary emphysema. Thorax 1982; 37: 667-670.

12 Martinez F, Montes de Oca M, Whyte R, et al. Lung volume reduction improves dyspnea, dynamic hyperinflation and respiratory muscle function. Am J Respir Crit Care Med 1997; 155: 19841990.

13 O'Donnell D, Lam M, Webb KA. Spirometric correlates of improvement in exercise performance after anticholinergic therapy in chronic obstructive pulmonary disease. Am J Respir Crit Care Med 1999; 160: 542-549.

14 Calverley PM, Burge PS, Spencer S, et al. Bronchodilator reversibility testing in chronic obstructive pulmonary disease. Thorax 2003; 58: 659-664.

15 Tashkin DP, Celli B, Decramer M, et al. Bronchodilator responsiveness in patients with COPD. Eur Respir J 2008; 31: 742-750.

16 Burge PS, Calverley PM, Jones PW, et al. Randomized, doubleblind, placebo controlled study on fluticasone propionate, in patients with moderate to severe chronic obstructive pulmonary disease: the ISOLDE trial. BMJ 2000; 320: 297-303.

17 The Lung Health Study Research Group. Effect of inhaled triamcinolone on the decline in pulmonary function in chronic obstructive pulmonary disease. N Engl J Med 2000; 343: 1902-1909.

18 Vestbo J, Sorensen T, Lange $\mathrm{P}$, et al. Long-term effect of inhaled budesonide in mild and moderate chronic obstructive pulmonary disease: a randomised controlled trial. Lancet 1999; 353: 1819-1823.

19 Pauwels RA, Löfdahl CG, Laitinen LA, et al. Long-term treatment with inhaled budesonide in persons with mild chronic obstructive pulmonary disease who continue smoking. N Engl J Med 1999; 340: 1948-1953.

20 Calverley P, Pauwels R, Vestbo J, et al. Combined salmeterol and fluticasone in the treatment of chronic obstructive pulmonary disease: a randomized controlled trial. Lancet 2003; 361: 449-456.

21 Tashkin DP, Celli B, Senn S, et al. A 4-year trial of tiotropium in chronic obstructive pulmonary disease. N Engl J Med 2008; 359: 1543-1554.

22 Dellacà RL, Pompilio PP, Walker PPP, et al. Effect of bronchodilation on expiratory flow limitation and resting lung mechanics in COPD. Eur Respir J 2009; 33: 1329-1339. 
23 Aaron SD, Vandemheen KL, Fergusson D, et al. Tiotropium in combination with placebo, salmeterol, or fluticasone-salmeterol for treatment of chronic obstructive pulmonary disease: a randomized trial. Ann Intern Med 2007; 146: 545-555.
24 Welte T, Miratvilles M, Hernandez P, et al. Efficacy and tolerability of budenoside/formoterol added to tiotropium in patients with chronic obstructive pulmonary diseases. Am J Respir Crit Care Med 2009; 180: 741-750. 